\title{
UnA ASPIRACIÓN EXISTENCIAL: PlatÓN Y KIERKEGAARD \\ FRENTE A LA RELACIÓN DEL INDIVIDUO CON LA VERDAD
}

\author{
Jesús René Flores Castellanos \\ Universidad Iberoamericana, México
}

\section{Resumen}

En este trabajo pretendo relacionar las concepciones de Platón y Kierkegaard acerca de la verdad, mostrando que para ambos autores ésta no puede ser comprendida sin su manifestación en la existencia de un individuo concreto, lo cual termina por mostrarla como una aspiración existencial, es decir, como una continua búsqueda por encarnarla. Frente a una concepción tradicional de la verdad, en la que el sujeto es un pasivo contemplador cuyo intelecto debe adecuarse a la realidad, la idea de verdad que nos presentan ambos pensadores nos permite caracterizarla como la relación vital activa del individuo concreto con el conocimiento y su situación existencial.

Palabras clave: Platón, Kierkegaard, verdad, existencia.

\section{Abstract}

In this paper I intend to relate the conceptions of Plato and Kierkegaard about the truth, showing that for both authors it cannot be understood without its manifestation in the existence of a concrete individual, which ends up showing it as an existential aspiration. Faced with a traditional conception of truth, in which the subject is a passive contemplator, whose intellect must be adapted to reality, the idea of truth presented to us by both thinkers allows us to characterize it as the active vital relation of the concrete individual with knowledge and his concrete existential situation.

Key words: Plato, Kierkegaard, truth, existence.

A veces me miro en el espejo y trato de encontrarme; me agarro el cabello, observo mis manos, pero no me encuentro. Escribo, tomo un libro cualquiera y comienzo a leerlo; encuentro respuestas, pero no las veo. Todo se va en el mismo instante en que creo por fin empezar a comprenderlo.

Recibido: 21 de julio de 2018; Aceptado: 23 de agosto de 2018. 
En este trabajo pretendo relacionar las concepciones platónica y kierkegaardiana de la verdad, mostrando que para ambos autores ésta no puede ser comprendida sin su manifestación en la existencia de un individuo concreto, lo cual termina por mostrarla como una aspiración vital, es decir, como una continua búsqueda por encarnarla. Con ello, espero también contribuir a la erradicación de algunos prejuicios que, a pesar de ya haber sido señalados por importantes comentaristas, aún se encuentran presentes como lugares comunes: se trata de las concepciones de que Platón, por un lado, es un filósofo en exceso sistemático y con una concepción radicalmente objetiva y separatista de la verdad ${ }^{1}$, como si ésta fuera un objeto y, por el otro, de que la noción de verdad que plantea Kierkegaard lo convierte en un pensador radicalmente anti-sistémico e incluso, como algunos le han llegado a denominar, irracionalista.

\section{Platón: el diálogo como aspiración existencial a la verdad.}

Un pasaje casi al comienzo del Fedón ha sido objeto de controversia filológica. Como sabemos, el diálogo muestra los últimos momentos de Sócrates, y el personaje que nos narra los hechos se trata de aquél que da nombre al diálogo. El fragmento en cuestión es el 58e, donde Fedón, interrogado por Equécrates y al inicio de su relato acerca de la muerte del filósofo, comenta:

En verdad experimenté una extraña sensación mientras estaba a su lado [de Sócrates]. Pues la idea de estar asistiendo a la muerte de un hombre que era mi compañero no suscitaba en mí piedad, pues ese bombre (áner) me parecía feliz, Equécrates, tanto por su actitud como por sus palabras, tan impertérrita y noblemente murió ${ }^{2}$.

La discusión, que para algunos puede parecer bizantina, proviene de la forma en la que debe ser leído ese anér, ya sea como acompañado del pronombre bó o no, ya que algunos manuscritos nos otorgan una versión, y otros la

${ }^{1}$ Quizá la máxima expresión de esta concepción de la filosofía platónica sea la de la llamada Escuela de Tubinga, representada especialmente por Hans Joaquim Krämer, y que concibe el pensamiento de Platón como el intento de establecer un sistema deductivo cerrado a partir de dos principios fundamentales. Cfr. Hans Joachim Krämer, Plato and the Foundations of Metaphysics, trad. de John R. Catan, Nueva York: University of New York Press, 1990.

${ }^{2}$ Fedón, 58e. La traducción, que empleo a lo largo de este trabajo es de Enrique Ángel Ramos, de su edición crítica y bilingüe: Apología de Sócrates. Fedón, Madrid: Consejo Superior de Investigaciones Científicas, 2002. 
otra. La lectura que tomemos cambia el énfasis en el aspecto concreto del hombre al que se hace referencia: en efecto, si tomamos la opción carente de pronombre tendríamos una forma más impersonal: "un hombre feliz", mientras que, si nos decidimos por la lectura con pronombre, tendríamos una lectura que tomaría como sujeto concreto al hombre Sócrates, como la de nuestro traductor: "ese hombre era feliz"3.

Me parece que lo que a primera vista puede ser sólo una discusión de carácter filológico, y únicamente como tal ha sido desarrollada, podría contener importantes implicaciones filosóficas. En efecto, decidirse por la segunda lectura, la que tiene pronombre, nos otorgaría un Platón más preocupado por hacer énfasis en la situación concreta en la que se encontraba un individuo concreto: Sócrates. Defiendo dicha interpretación, ya que me parece acorde con las concepciones filosóficas de Platón en otros diálogos y con el contexto de esta obra en general. Así, la frase de Fedón nos mostraría la dialéctica que se establece entre el universal ántrophos (el hombre en cuanto concepto abstracto y universal), y el énfasis que se establece al utilizar la forma hó anér señalando la situación concreta en la que muere un individuo singular ("ese hombre moría feliz"). No se trata de la muerte de un hombre en abstracto, sino de la forma en la que Sócrates enfrentó su muerte, a partir de su situación como individuo particular ${ }^{4}$.

Si Sócrates pudo enfrentar su muerte de una manera feliz, es porque estaba convencido de que la verdad acerca de este fenómeno no era lo que la mayoría de los hombres pensaban: en efecto, para el filósofo ateniense, por lo menos como nos lo muestra Platón en este diálogo, la muerte no era una cuestión negativa, sino positiva, ya que sólo a través de ella el ser humano podía alcanzar su plenitud, la cual consiste, según nuestro autor, en la contemplación de las Formas eternas a partir de la liberación del alma racional de su tumba corporal.

${ }^{3}$ Para más información acerca de la discusión sobre cómo traducir este pasaje, cfr. la nota al pie en la edición citada en la nota anterior, p. 72.

${ }^{4}$ Resulta de mucho interés rastrear el origen de la palabra griega anér en Homero: anér parece indicar un hombre particular referido al concepto de "héroe"; así, la heroicidad puede ser un aspecto general, aquél que toma el riesgo de morir a cambio de la gloria inmortal, pero la forma específica en la que la heroicidad se encarna varía de individuo a individuo: para Aquiles puede mostrarse en el riesgo que toma al saber que morirá si va a Troya, mientras que para Héctor se encarna en el defender con su vida a su patria y su familia. Para más información, cfr. el Prólogo de Óscar Martínez García, a su edición de la Ilíada, de Homero, Madrid: Alianza, 2016, pp. 38-51. 
Pero Platón, como es bien sabido, a pesar de tener esa idea acerca de la muerte, no pretende demostrarla en una especie de tratado filosófico de carácter impersonal, sino que apela a la forma del diálogo como la única que puede mostrarnos que la verdad de una idea no puede ser entendida sin su relación específica con individuos en diversas situaciones existenciales. Así, el Fedón nos mostrará diferentes posturas frente a la muerte de acuerdo a como la idea de ésta sea entendida y vivida por los diferentes interlocutores: las lágrimas de la esposa de Sócrates, y de su amigo Critón, así como el enfoque pitagórico de Simmias y Cebes, son el resultado de esta forma de aproximarse al conocimiento de la verdad. Bajo esta perspectiva, el diálogo platónico no nos mostraría posturas meramente intelectuales representadas por individuos, sino, por el contrario, individuos que han tomado ciertas posturas frente a la vida y que se ven encarnadas en su situación existencial específica. La búsqueda de la verdad que encontramos en las obras de Platón se encuentra relacionada necesariamente con la forma de vida de todos los interlocutores que participan en sus Diálogos.

Así, esta forma de entender la relación con la verdad parece ser la que se encuentra detrás de prácticamente todos los diálogos platónicoss: en efecto, la pregunta por la verdad universal y objetiva de algún tema o concepto en particular que encontramos en otras obras sólo presenta su sentido pleno a partir de la situación concreta que están viviendo los interlocutores: en el Lisis, la pregunta por la amistad surge a raíz de la relación entre Hipotales y Lisis; en el Protágoras, la pregunta por la mejor forma de vida se plantea a partir del interés que tiene Hipócrates por educarse con el sofista, e incluso en el Parménides encontramos la relación de la discusión abstracta sobre las Formas con el interés existencial que puede tener en ella un joven Sócrates, etc.

La estructura de los diferentes diálogos siempre apunta a un paso de la situación específica, en la que surge y tiene sentido la pregunta por algo, a la resolución más objetiva del problema, aunque siempre buscando la respuesta en diálogo y, posteriormente, a un retorno a la situación concreta y a las consecuentes reflexiones acerca de la modificación de la forma de vida que debería realizarse a partir de lo descubierto ${ }^{6}$.

${ }^{5}$ Alguien quizá pretendería excluir el Timeo debido a su carácter más expositivo y sin tanto recurso al diálogo; sin embargo, me parece que la exposición que encontramos en dicha obra sigue siendo realizada por un personaje concreto con una situación individual particular: Timeo, y no una razón abstracta que utiliza un lenguaje impersonal.

${ }^{6}$ En el caso de los diálogos tardíos, esta estructura parece modificarse un poco y hacer más énfasis en los conocimientos objetivos; sin embargo, desde mi punto de vista, Platón nunca perdió el interés por la relación existencial que el individuo debe establecer con el 
Tomemos el caso del Fedón, diálogo donde queda mejor expuesta esta relación debido a su carácter de narración de un enfrentamiento con la situación límite de la muerte: la pregunta por la verdad objetiva de la muerte se presenta con sentido en una situación en la que un hombre concreto, Sócrates, va a morir. La investigación se realiza apuntando a la búsqueda de una solución objetiva, aunque lo que aporten a la discusión los diferentes interlocutores no pueda ser separado del todo de sus vivencias, ya que no dejan de ser individuos particulares. Simmias y Cebes, por ejemplo, hablarán desde su pitagorismo, pero con el objetivo en mente de encontrar la verdad universal y objetiva, válida no sólo para los pitagóricos, acerca de la muerte. Una vez que se ha encontrado ésta, es decir, una vez que tenemos la verdad del ántrophos, debemos regresar al individuo concreto, anér, para dilucidar cómo debe ser encarnada por éste en la situación específica en la que se encuentra; en este caso, Sócrates, el ateniense condenado por el démos, debe afrontar la muerte sin miedo y lleno de esperanza en lo que le espera después, debido a su constante aspiración a una vida justa.

La forma concreta en la que Sócrates enfrenta la muerte, esto es, lleno de esperanza, nace de su situación particular: en efecto, no se trata de la forma en la que todos deberían enfrentarla, ya que nuestro filósofo deja muy claro que su esperanza nace de que él ha dedicado su vida al cultivo de la filosofía:

Pues ahora quiero daros a vosotros, mis jueces, la razón de por qué me parece natural que un hombre que ha pasado en verdad la vida dedicado a la filosofía se muestre animoso cuando está a punto de morir y esté bien esperanzado de que allá va a lograr los mayores bienes, una vez que muera ${ }^{7}$.

Del hecho de encontrar lo que parecen ser verdades objetivas no se sigue que quede absolutamente clara la forma en la que cada individuo deba encarnarlas. Para Sócrates la filosofía es una forma de vida, que debe ser realizada en cada individuo particular, y no una ciencia abstracta que no tenga repercusiones en la existencia de las personas. Algunas de ellas incluso rechazan hacerlo, como es el caso de Calicles y Polo en el Gorgias, los cuales terminan por lanzar amenazas contra Sócrates en lugar de aceptar y vivir lo que el examen dialéctico ha mostrado. Discernir la relación que debo establecer con la verdad objetiva parece estar en relación con el concepto de

conocimiento de la verdad. La principal preocupación de nuestro filósofo parece haber sido constantemente la mejor forma de vivir.

${ }^{7}$ Fedón, 63d. 
phrónesis (traducido generalmente como "prudencia"), tan valorado por los griegos, y el de diké ("justicia”) tal como lo formula Platón en el libro IV de la República: "hacer lo que corresponde a cada uno", aspecto que no queda del todo claro y que debe ser dilucidado a partir del diálogo y la reflexión personal. Así, por ejemplo, la importante obra de la República se presenta como la propuesta de un ideal que nos permite tener una dirección hacia la cual dirigir los asuntos públicos y personales, sin que excluya el papel que cada individuo debe jugar a la hora de ordenar su vida y su participación en el mundo de la comunidad: a los guardianes les toca velar por el bien común, a los artesanos cumplir con la producción que les corresponde, etc.; a su vez, dentro de cada uno de estos grupos, cada individuo debe encontrar la manera en la que le toca relacionarse con su clase y las demás.

Esta postura de Platón nos permite entender por qué, a pesar de su confianza en que la razón podría alcanzar objetividad, la verdad como encarnación en el individuo concreto se presenta como un ideal, como una aspiración que debe ser vivida de manera existencial y en reflexión continua. El diálogo y la búsqueda de la virtud nunca deben cesar y Sócrates fue un individuo trascendental porque logró culminar esa aspiración en su vida particular: su conocimiento objetivo acerca de la muerte del ántrophos lo llevó a encarnar la felicidad como anér en el momento de su muerte, cosa que Critón, por ejemplo, a pesar de haber estado presente en el mismo diálogo acerca de la situación mortal del ser humano, no logró encarnar, por lo menos en ese momento, y terminó por ceder a la desesperación por la muerte de su amigo.

Es esta noción de la verdad como aspiración vital, que debe ser encarnada existencialmente, y sobre la que tenemos que estar reflexionando continuamente, buscando el papel que debemos jugar a partir de lo que encontramos objetivamente, y la culminación de ello en la figura de Sócrates, lo que llevó a Platón a afirmar, en boca de Fedón que: "Éste fue el final, Equécrates, de nuestro amigo, de un hombre, como nosotros podríamos afirmar, de entre aquellos a quienes conocimos, el mejor y sin parangón el más sensato (phronimotátu) y el más justo (dikaiotátu)" ${ }^{8}$. Es decir, aquel anér que se ejercitaba continuamente en la reflexión y la acción para encontrar y encarnar la verdad. La vida de Sócrates es una vida en constante lucha, como la del anér heroico de la épica, sólo que en este caso no es una lucha

${ }^{8}$ Fedón, 118a. Nótese el empleo de los dos conceptos mencionados anteriormente: Sócrates posee phrónesis porque supo dilucidar la relación que la verdad objetiva tenía con él en el momento de su muerte, y Sócrates posee diké porque hizo lo que le correspondía a partir de dicha relación. 
por la gloria inmortal, sino por mostrar con su vida concreta, una forma en la que puede ser encarnada la verdad universal.

\section{Søren Kierkegaard: la verdad subjetiva.}

Para el caso de Kierkegaard tomaré como base el texto Postscriptum cientifico y no definitivo a Migajas filosóficas, ya que es aquí donde encontramos más desarrollado el concepto clave para este trabajo: la verdad subjetiva9. En la introducción, el autor del tratado, Johannes Climacus, seudónimo de Kierkegaard, nos comenta que el problema que será desarrollado a lo largo de la obra será el problema del cristianismo, pero que éste puede ser enfocado de dos formas.

La primera planteándolo de manera objetiva, ya sea histórica o filosófica. Si lo planteamos de una manera objetiva histórica, entonces estaríamos preguntando por la verdad histórica de la figura de Jesús, de sus seguidores, de la datación de los textos, etc. Si lo planteamos de manera objetiva filosófica, entonces estaríamos preguntando por la verdad objetiva, eterna y universal, de las doctrinas enseñadas por el cristianismo, esto es, si se corresponden o no con la realidad en tanto independiente del sujeto particular.

Pero lo que Climacus pretende no es lo anterior, por lo menos no a la manera en la que lo haría un tratado sistemático de teología científica. Lo que nuestro seudónimo pretende es establecer el problema de una manera subjetiva, lo cual significa lo siguiente:

El objeto del problema no es la verdad del cristianismo, sino la relación del individuo con el cristianismo, de manera que de lo que aquí se trata no es del afán sistemático del individuo por clasificar las verdades del cristianismo en parágrafos, sino de la preocupación del individuo infinitamente interesado por su relación con dicha doctrina. Para expresarlo de la manera más sencilla posible (haciendo uso de mí mismo en el experimento): "Yo, Johannes Clima-

${ }^{9}$ Surge aquí el problema, típico en el estudio del pensamiento kierkegaardiano, de si podemos atribuir a Kierkegaard o no lo dicho por un seudónimo, en este caso Climacus. Me parece que el concepto de verdad subjetiva que aparece en esta obra será una constante en la obra de Kierkegaard y, por lo tanto, sí podemos hacerlo, aun cuando no estemos tan de acuerdo en la interpretación particular que de este concepto otorga Climacus a la hora de mostrar cómo se debe encarnar en la existencia. Es decir, lo que plantea Climacus acerca de cómo se debe entender la relación de la verdad con el sujeto sería válida para Kierkegaard, si bien el contenido específico que Climacus otorga a la verdad podría no serlo. 
cus, nacido en esta ciudad, de treinta años de edad, humano sin más ni más como la mayoría de la gente, admito que, exactamente igual que a una criada o a un profesor, me espera un bien supremo que se llama salvación eterna. He oído decir que el cristianismo es la condición para alcanzar dicho bien, por lo que mi pregunta ahora es la siguiente: ¿cómo puedo yo entrar en relación con dicha doctrina?" 10

Como se ve, no parece haber una crítica como tal al planteamiento objetivo por la verdad del cristianismo, sino que se nos hace ver que la relación que un individuo particular debe establecer con el cristianismo es un problema que debe ser planteado aparte de la objetividad de esta doctrina. Climacus no dice en ningún momento que las investigaciones objetivas deban ser abandonadas, si bien sí deben ser puestas en su justo lugar.

La crítica que aparece en esta obra no es al sistema en tanto tal, sino a los individuos que piensan que el cristianismo enfocado como un sistema de verdades, con sus pretensiones de objetividad, les dará la respuesta absoluta a qué es lo que deben hacer para entrar en relación con él, siendo ésta una cuestión que sólo el mismo individuo debe responder a partir de su situación existencial específica.

El problema aquí, entonces, no es la objetividad del cristianismo, sino la relación subjetiva que un individuo concreto establece con él. Hay que evitar caer en la trampa de pensar que para Kierkegaard no tenía importancia la investigación sistemática acerca de la historia y la teología del cristianismo, si bien sí es muy claro en afirmar que el interés existencial que inclina al individuo hacia él tiene un lugar primordial.

Climacus dirá que el solo aprender a enfocar el cristianismo a partir de la perspectiva subjetiva, es decir, de la relación de un individuo concreto con la verdad del cristianismo es ya un problema en sí mismo: el problema del "llegar a ser subjetivo". Nuestro autor dedica incluso toda una sección de la obra sólo a que se comprenda lo que pretende decir con estas consideraciones. En efecto, como queda claro en el título de la segunda sección: "El problema subjetivo, o cuál debe ser la índole de la subjetividad para que el problema pueda mostrársele"11, lo único que se pretende ahí es llevar al lector a un estado en el que logre comprender el problema mismo de la relación entre el individuo y la verdad.

${ }^{10}$ Søren Kierkegaard, Postscriptum no cientifico y definitivo a "Migajas filosóficas", trad. Javier Teira y Nekane Legarreta, Salamanca: Sígueme, 2010, pp. 27-28.

${ }^{11}$ Kierkegaard, Postscriptum..., p. 133. 
Si alguien pretende encontrar la verdad absoluta y objetiva a partir de los estudios sistemáticos, ya sea históricos, ya filosóficos, del cristianismo y que esto le otorgará la fe y la respuesta a qué debe hacer en su situación existencial, entonces es cuando se mostrarán los límites del sistema y la empresa fracasará. Llegar a ser subjetivo, plantear el problema de mi relación existencial y particular con el cristianismo, es decir, llegar a vivir la fe y decidir a partir de la pasión de mi interioridad, nunca será un problema que pueda plantearse y responderse a partir de consideraciones sistemáticas.

Todo lo anterior, dicho sea de paso, si lo vemos de manera objetiva genera una paradoja: una verdad eterna debe encarnarse en una existencia particular e histórica, lo cual parece contradictorio, pero es la esencia misma de la doctrina cristiana. Cristo, Dios mismo, es decir, la verdad objetiva y universal, tomó carne en un momento histórico concreto, y en dicho momento vivió de una manera histórica específica, sin dejar de ser lo universal. Este llamado paradójico es el que el cristianismo hace a todo individuo que se acerca a él y muestra que la única forma de entender la verdad es mediante la encarnación, mediante la relación vital del individuo concreto con lo universal.

Unas páginas más adelante, Climacus otorgará una definición de lo que podría ser la verdad una vez que hemos planteado el problema de manera subjetiva:

He aquí una definición tal de la verdad: la verdad es la incertidumbre objetiva sostenida en la apropiación de la interioridad más apasionada; tal es la más excelsa verdad que hay para un existente. (...) Objetivamente, él sólo tiene la incertidumbre, pero es esto precisamente lo que tensa la pasión infinita de la interioridad, y en esta aventura consiste justamente la verdad, en elegir la incertidumbre objetiva con pasión infinita. (...) Tal definición de la verdad es una paráfrasis de la fe. ${ }^{12}$

Si planteamos objetivamente el problema, nunca tendremos la solución de la verdad del cristianismo para un individuo existente. Si alguien decide creer en Dios, lo hará no porque lea un tratado sistemático sobre Él; y si alguien decide no hacerlo, no lo hará por más que lea mil tratados de teología. El sistema no toca la interioridad, la subjetividad, dejando únicamente una tensión que debe ser resulta mediante la pasión. Objetivamente sólo tenemos incertidumbre, pero una que permite al individuo tomar una decisión a partir de su ámbito subjetivo, misma que necesariamente se verá reflejada en su forma de vivir.

${ }^{12}$ Kierkegaard, Postscriptum..., p. 205. 
La decisión de creer en la verdad de Dios y del cristianismo o no es una cuestión más de la pasión y la subjetividad que de la mera razón y la objetividad, lo cual, insisto, no anula que podamos escribir tratados sistemáticos sobre Dios, pero sí deja de lado el hecho de que podamos encontrar la verdad última sobre nuestra existencia individual en ellos.

Hay que ser muy precisos y distinguir dos planos en la relación: por un lado, objetivamente no puedo conocer la respuesta a si Dios existe o no, a si se encarnó en la persona de Jesús o no, etc.; esto siempre será el ámbito de la incertidumbre. A partir de esta tensión originada por la falta de certezas, la individualidad se ve movida a tomar una decisión mediante la pasión; pero, una vez ocurrido este movimiento, y sin que se tengan que dar separados, ocurre también la decisión interior acerca de cómo encarnar específicamente aquello que se ha decidido. Así, no basta con creer subjetivamente en Dios, sino que la pasión con la que lo hago me lleva necesariamente a plantear la cuestión de cómo se encarna en mi vida: sólo este doble movimiento puede manifestar la verdad para un existente en una situación particular.

Tomemos como ejemplo la vida misma de Kierkegaard. Una vez que sintió un llamado profundo hacia la divinidad, nuestro escritor parece haber quedado convencido pasionalmente de que lo que tenía que hacer era convertirse en un escritor religioso que transformara la conciencia de sus contemporáneos. Objetivamente no podía tener ninguna certeza, ni de que Dios existiera, ni de que esa era la "vocación” que se le pedía realizar. Sin embargo, mediante su interioridad y su pasión, decidió que esa era la forma de encarnar la verdad del cristianismo en su vida. Lejos de buscar que un tratado de ética teológica le dijera qué hacer específicamente, buscó la manera de encarnar la verdad a partir de su individualidad específica, lo cual no quiere decir que quizá no se haya apoyado en ciertas consideraciones teológicas. Las consecuencias de una decisión plenamente subjetiva y apasionada como esa son evidentes ${ }^{13}$.

La verdad subjetiva, aquella que dota de sentido a nuestra vida, es una cuestión que objetivamente siempre será una incertidumbre. Yo puedo creer en las verdades del cristianismo, leer a los grandes teólogos, aun así, responder qué quiere la divinidad de mí (aparte de la cuestión de su misma existencia) nunca podrá ser resuelto por este camino, lo único que

${ }_{13}$ Debo las consideraciones acerca de los planteamientos vocacionales del propio Kierkegaard al Dr. Luis Guerrero Martínez, tanto las que me ha compartido en sus siempre interesantes clases y pláticas personales, como en su libro La verdad subjetiva. Søren Kierkegaard como escritor, México DF: Universidad Iberoamericana, 2004. 
la subjetividad puede hacer es, mediante su pasión, afirmar una elección, y apropiarse de ella, es decir, encarnarla en sus acciones, sabiendo que nunca tendrá la certeza absoluta de que eso es verdad de manera objetiva.

Sólo porque no tengo una seguridad objetiva es que la pasión "se tensa" y la subjetividad puede aparecer. En otras palabras, sólo porque no tenemos una certeza en la relación que debo establecer con la verdad, es como podemos elegir y convertirnos en lo que propiamente somos. Sólo la incertidumbre objetiva permite el paso para "llegar a ser subjetivos" y, con ello, vivir nuestra pasión y nuestra libertad, apropiarnos nuestra fe. De lo contrario, si las respuestas fueran completamente ciertas y evidentes, la subjetividad no existiría, y nos convertiríamos en meros entes impersonales, con lo que la fe no sería posible. Esto es precisamente lo que parecen buscar aquellos que todo lo quieren encontrar en la elaboración del sistema que anule al individuo y su pasión, pero esto, como nos recuerda nuestro filósofo, va en contra no sólo de la fe, sino de la misma subjetividad como tal. La relación que un individuo establece con el cristianismo, la verdad, es una cuestión, entonces, que sólo le incumbe a él y su interioridad.

\section{Platón y Kierkegaard: la verdad como relación vital subjetiva}

Una vez que hemos trazado estas consideraciones, podemos hacer algunas reflexiones acerca de lo que significa la verdad para los pensadores que hemos tratado. En un primer momento, sobre todo en el caso de Platón, podríamos pensar que la verdad es una cuestión separada y objetiva, como si fuera una cosa que tenemos que asir en orden a comprender la realidad. La definición clásica de la verdad, "la adecuación de la mente con la realidad", bien podría encajar dentro de este parámetro. Kierkegaard también nos ha llevado a pensar que el cristianismo mismo es capaz de ser planteado de manera objetiva, a partir de una comprensión de la verdad como esta.

Sin embargo, al profundizar en las reflexiones de estos pensadores descubrimos una nueva forma de entender la esencia de la verdad. La diferencia radica en la idea de que la verdad no es un objeto, sino una relación del individuo con el conocimiento de las Formas, en el caso de Platón, y con las doctrinas del cristianismo, en el caso de Kierkegaard. Bajo esta perspectiva, lo fundamental de la verdad no radica en el conocimiento de lo que sea la realidad, sino en la relación subjetiva que se establece con ella, es decir, la forma en la que vivimos y encarnamos lo que consideramos verdadero. Se podría distinguir incluso entre el "conocimiento", que apunta 
a lo universal, y la "verdad", que manifiesta su encarnación concreta en un individuo.

El movimiento parece ser triple en ambos pensadores: primero, se parte de un individuo en una situación específica que tiene cierto interés, de ahí se pasa a plantear el problema a partir de consideraciones universales, para finalmente regresar al sujeto particular y la forma propia en la que encarnará aquello universal, modificando por completo su situación existencial.

En el caso de Platón, en primer lugar, el interés del individuo radica en encontrar la mejor forma de vida, la virtud, y el conocimiento de las Formas que me permitirán descubrirlo ${ }^{14}$. Esta búsqueda se ve reflejada, como se dijo, en las diferentes situaciones específicas de los interlocutores que llevan a preguntar por la esencia de diferentes virtudes, conocimientos, etc. De ahí se llega propiamente a la discusión dialéctica que busca establecer definiciones válidas universalmente. Por último, y quizá lo más importante, es necesario que cada individuo se plantee cómo debe llevar a su propia existencia aquello que se ha conocido. El máximo ejemplo de esta encarnación vital de la verdad lo dio, para Platón, Sócrates en el momento de su muerte.

En el caso de Kierkegaard, como se ha visto, el interés del individuo se origina al buscar la salvación y el llegar a ser quien realmente es. Para ello, en segundo lugar, busca las doctrinas con pretensión universal del cristianismo. Finalmente, decide apasionadamente cómo encarnará en su propia vida aquellas doctrinas. La verdad, según el mismo planteamiento cristiano, es la encarnación de lo universal en lo particular, de Dios en un momento histórico, y cada individuo cristiano debe establecer esa verdad en su propia existencia mediante su libertad y su pasión.

A partir de estas consideraciones podríamos hacer algunas reflexiones acerca de la fórmula tradicional de la verdad. Ésta, como se ha dicho, establece que la verdad es la adecuación del intelecto con la realidad; es decir, se establece una relación entre dos polos. Sin embargo, lo que Platón y Kierkegaard nos han mostrado es que es necesario entender que la relación no puede ser entendida de manera pasiva, como si el sujeto fuera puro intelecto que se limita a recibir el conocimiento. La verdad, para estos pensadores, es una relación activa con algún conocimiento o doctrina de carácter universal, pero que no se limita a una pasividad, sino que tiene que

${ }^{14}$ Recuérdense las palabras de Sócrates en el Gorgias: "Nuestra conversación trata sobre lo que más en serio debería tomarse un hombre, por poco entendimiento que tenga; ¿qué podría serlo más que esto?: de qué forma hay que vivir” (500c). Trad. de Ramón Serrano y Mercedes Díaz, Madrid: Consejo Superior de Investigaciones Científicas, 2000. 
ser establecida existencialmente en la vida de cada individuo. La verdad es una relación continuamente afirmada y vivida por un existente particular que conoce, sí, lo universal, pero que lo encarna de una manera específica en su vida mediante una decisión, misma que tiene que ser continuamente reflexionada y sostenida, como si fuera un combate. La verdad es el establecimiento continuo de una relación vital entre el sujeto y la realidad.

\section{Conclusiones}

Tanto para Platón, como para Kierkegaard, la verdad no puede ser entendida si no se encarna en un individuo concreto, si no se realiza una apropiación de ella en la existencia. La verdad objetiva, ya sea alcanzable, como quiere Platón, ya sea una incertidumbre, como la plantea Kierkegaard, no tiene sentido si no es reflexionada y traducida en las acciones de un existente singular. Ni Platón es aquél pensador en exceso sistemático que cree en una sola verdad separada y en el individuo como un mero contemplador de ella, ni Kierkegaard es el pensador radicalmente antisistémico que no otorga ningún lugar a las consideraciones objetivas sobre la verdad. Lo que ambos pensadores, a pesar de sus diferencias, parecen señalar, es que es necesario para cualquiera de nosotros el reflexionar sobre cómo vamos a establecer nuestra propia relación con la realidad y actuar en consecuencia y éste es un ejercicio que nunca debe terminar.

El epígrafe de este trabajo, de una obra de Paola Iridee ${ }^{15}$, nos señala una situación existencial en la que quizá muchos de nosotros nos hemos encontrado alguna vez: sintiendo la necesidad de saber quiénes somos, nos contemplamos en un espejo, tratando de encontrar en la expresión física y objetiva de lo material la respuesta que buscamos. El esfuerzo resulta vano. Nuestro siguiente paso es tomar los libros, buscar desesperadamente en el conocimiento científico, literario o incluso religioso nuestra identidad. Quizá en un primer momento consideramos que estamos más cerca, que las grandes mentes del pasado y del presente serán las guías adecuadas para nuestro viaje iniciático, tal como Virgilio condujo a Dante a su propio infierno para llevarlo después al Paraíso. Pero todo parece desmoronarse después. Al igual que a Fausto, los libros terminan por generarnos una sensación de que lo buscado no puede venir de ellos, que no tenemos una

${ }^{15}$ Iridee, Paola, "Sin título", en Letras Primigenias, Cuautitlán (México): Ediciones el Nido del fénix, 2015, p. 41. 
comprensión real de lo que somos a través de ellos, por lo menos no de la manera en la que los hemos utilizado hasta ahora.

Pero es que, quizá, hemos considerado mal lo que sea la verdad y nuestra identidad. Quizá hemos pensado que recibiríamos la respuesta de una manera pasiva, como meros contempladores de una realidad externa a nosotros, sin darnos cuenta, junto con Platón y Kierkegaard, que la única forma de encontrarnos a nosotros mismos es mediante la acción apasionada y libre, mediante la decisión individual de encarnar, en nuestra situación particular, aquello que hemos encontrado en nuestra búsqueda científica, literaria y religiosa. La respuesta específica a cómo hemos de hacerlo nunca podrá otorgarla la universalidad, y tampoco podremos tener nunca la seguridad de que la hemos encarnado adecuada y completamente. Lo que nos queda es la constante reflexión y lucha, tanto para comprender mejor lo universal, como para establecerlo en las circunstancias existenciales específicas que nos corresponden. La única identidad real, la única verdad acerca de nosotros es la acción, y ésta sólo se da a partir de consideraciones teóricas y pasionales dentro de una situación existencial específica. Somos relación, tanto hacia los conocimientos como hacia nuestra situación. Platón y Kierkegaard siempre estarán ahí para recordárnoslo, si bien no para otorgarnos la respuesta específica acerca de cómo debemos vivir. Sus obras son el mejor ejemplo y la mayor expresión de que la verdad es una cuestión de ejercicio constante y sin final. La verdad no es una cosa, sino una aspiración existencial.

\section{Bibliografía}

Kierkegaard, Søren, Postscriptum no científico y definitivo a Migajas filosóficas, trad. Javier Teira y Nekane Legarreta, Salamanca: Sígueme, 2010.

Guerrero Martínez, Luis, La verdad subjetiva. Søren Kierkegaard como escritor, México, D.F.: Universidad Iberoamericana, 2004.

Homero, Ilíada, trad. Óscar Martínez García, Madrid: Alianza, 2016, pp. 38-51.

Iridee, Paola, Letras Primigenias, Cuautitlán (México): Ediciones el nido del fénix, 2005.

Krämer, Hans Joachim, Plato and the Foundations of Metaphysics, trad. de John R. Catan, Nueva York: University of New York Press, 1990.

Platón, Apología de Sócrates. Fedón, edición crítica y blingüe de Enrique Ángel Ramos Jurado, Madrid: Consejo Superior de Investigaciones Científicas, 2002.

Gorgias, edición crítica y bilingüe de Ramón Serrano y Mercedes Díaz, Madrid: Consejo Superior de Investigaciones Científicas, 2000. 